\title{
O PAPEL DO GESTOR EM UMA AUTARQUIA PÚBLICA EM RELAÇÃO ÀS PRÁTICAS DE RESPONSABILIDADE SOCIAL E AMBIENTAL
}

\author{
Vanessa Menegol \\ vanessamenegol@gmail.com \\ Centro Universitário Metodista - IPA - RS / Brasil
}

\section{RESUMO}

A responsabilidade social é discutida em todos os setores da sociedade, avançando e mudando o mundo das organizações e abrindo portas para o conceito de sustentabilidade. Neste sentido o presente trabalho buscou descrever o papel do gestor e sua relação com as práticas de responsabilidade social e ambiental da autarquia pública Conselho Regional de Administração. Para tanto, foi realizado um estudo de caso, com métodos de abordagem qualitativa. Os objetivos deste estudo foram: a caracterização do perfil dos gestores da autarquia pública e suas motivações para a prática das ações de responsabilidade social; a verificação de como a autarquia pública desenvolve suas ações de responsabilidade social e ambiental; a descrição do plano de ação do CRA-RS e a inserção da responsabilidade social e ambiental no planejamento estratégico da autarquia pública pesquisada. A coleta de dados foi realizada por meio de observação, entrevistas semiestruturadas e análise de documentos. Dentre os resultados, foi possível visualizar que a empresa pesquisada mantém em sua prática diária preceitos relacionados à responsabilidade social e ambiental. A entidade age pro ativamente em relação à responsabilidade social e ambiental e cumpre às questões correspondentes ao consumo, ao meio ambiente e à segurança do trabalho. O desafio da autarquia torna-se, assim, em manter, inovar e ampliar as práticas já exercidas. Conclui-se que, por meio da estruturação de seu planejamento estratégico e programas, os gestores demonstram a importância de implantar e disseminar as práticas de responsabilidade social em ambiental ampliando assim a qualidade de vida e o bem-estar das gerações atuais e futuras.

PALAVRAS-CHAVE: Responsabilidade Social Empresarial. Autarquia Pública. Sustentabilidade Organizacional. Práticas Sociais. 


\section{THE ROLE OF THE MANAGER IN A PUBLIC AUTHORITY IN RELATION TO SOCIAL AND ENVIRONMENTAL RESPONSIBILITY PRACTICES}

\section{ABSTRACT}

Social responsibility is discussed in all sectors of society, advancing and changing the world of organizations and opening doors to the concept of sustainability. In this sense the present study was to describe the role of the manager and its relation to social and environmental responsibility practices of public authority Regional Administration Council. The objectives of this study were to characterize the profile of managers of public authority and their motivations for the practice of social responsibility; verification of how the public authority develops its social and environmental responsibility actions; the description of the action plan of CRA-RS and the inclusion of social and environmental responsibility in the strategic planning of the surveyed public authority. The challenge of the local authority becomes thus to maintain, innovate and expand those already exercised practices. In conclusion, through the structuring of strategic planning and program managers demonstrate the importance of implementing and disseminating social responsibility practices in environmental thereby increasing the quality of life and well-being of current and future generations.

KEYWORDS: Corporate Social Responsibility. Public authority.OrganizationalSustainability. Social practices.

\section{INTRODUÇÃO}

Muito tem se falado nas responsabilidades das empresas perante seus funcionários, acionistas, clientes, enfim, todas as partes interessadas. Assim a responsabilidade social e ambiental se tornaram um fator de competitividade para os negócios, pois anteriormente o que identificava uma empresa competitiva era o preço de seus produtos, depois o foco foi a qualidade, mas no mundo contemporâneo se observa que as empresas devem investir permanentemente no aperfeiçoamento de suas relações com todos os públicos dos quais são dependentes e que tangenciam. 
O PAPEL do gestor em UMA AUTARQUia PÚblica EM RELAÇÃo ÀS PRÁTICAS DE RESPONSABILIDADE SOCIAL E AMBIENTAL

Neste contexto, a responsabilidade social empresarial (RSE) e a responsabilidade ambiental se tornaram instrumentos gerenciais para a capacitação e criação de condições de competitividade para as organizações, qualquer que seja seu segmento. Conforme Tachizawa (2006) a organização tradicional, hierárquica, encontra-se em fase de profundas modificações. Da mesma forma em que as barreiras estão degradadas na realidade política e econômica, a organização do futuro torna-se cada vez mais aberta. Destaca-se que o futuro das organizações estará diretamente ligado, mais do que a seu desempenho na produção de bens ou serviços, ao seu desempenho econômico-financeiro.

Desta forma, para isso acontecer, se deve buscar tecnologias avançadas e adequadas às necessidades que assumam seus insumos em fornecedores e que apresentem apropriadas condições de fornecimento, certificações de qualidade e postura social e ambientalmente corretas, que formem equipes de pessoas que comprometidas com os negócios das organizações, e com a consciência da responsabilidade social empresarial. Por serem pouco exploradas, as ações de responsabilidade social são um diferencial competitivo para garantir a sustentabilidade no contexto mundial globalizado (TACHIZAWA, 2006).

Segundo Ashley (2005) o caminho para uma sociedade sustentável requer uma nova perspectiva sobre os impactos das decisões e ações de todos os agentes sociais e, mais especificadamente dos stakeholders associados aos negócios da organização. A autora destaca que os principais desafios a serem vencidos para a conquista da responsabilidade social são a adoção de uma avaliação do desempenho das empresas tendo como referência o diálogo social com as partes interessadas. Como segundo desafio a autora aponta que as empresas devem transcender suas fronteiras, pois é preciso descentralizar o debate sobre responsabilidade social, que hoje tem a empresa

ReMAS - Revista Metodista de Administração do Sul, v. 2, N. 1, 2017 
como centro e origem de toda a responsabilidade social, passando a adotar novas atitudes (ASHLEY, 2005). Como terceiro desafio Ashley (2005) considera que as empresas deverão a partir de normas, princípios e valores assumidos e praticados, construir relações de confiança, reger suas relações por normas de conduta, incentivar e adotar parcerias que agreguem valor mutuamente e tomar decisões empresarias considerando aspectos econômicos, ambientais e sociais.

Karkotli e Aragão (2010) destacam que as práticas de responsabilidade social ou cidadania empresarial demonstram a certeza de que a empresa tem de realizar sua função interativa na sociedade, atuando de maneira proativa, e com sentido de igualdade, a comunidade que está em seu redor. A conscientização sobre a importância de realizar um papel de cidadania com a sociedade vem crescendo e já é uma realidade entre várias organizações.

Portanto o entendimento da responsabilidade social e ambiental é essencial para a gestão de uma organização, surgindo assim a problemática deste estudo, qual o papel do gestor em uma autarquia pública em relação às práticas de responsabilidade social e ambiental?

O assunto torna-se significativo para a área da administração, onde se percebe uma crescente preocupação e debate sobre questões ambientais e sociais das organizações, as soluções e inovações devem ser disseminadas entre o poder público e privado. O mercado está exigindo novos desafios aos gestores relacionados à sustentabilidade e responsabilidade social, adotando assim uma nova postura. Neste contexto, os objetivos deste estudo foram: a caracterização do perfil dos gestores de uma autarquia pública, no caso o Conselho Regional de Administração do Rio Grande do Sul (CRA-RS) e suas motivações para a prática das ações de responsabilidade social; a verificação de como a autarquia pública desenvolve 
O PAPEL do gestor em UMA AUTARQUia PÚblica EM RELAÇÃo ÀS PRÁTICAS DE RESPONSABILIDADE SOCIAL E AMBIENTAL

suas ações de responsabilidade social e ambiental; a descrição do plano de ação autarquia pública do CRA-RS e a inserção da responsabilidade social e ambiental no planejamento estratégico da autarquia pública pesquisada.

O tema abordado sobre responsabilidade social e ambiental busca inserir e estruturar os problemas enfrentados pelos gestores para desenvolver as práticas ambientais e ações sociais, sendo este um primordial para sobrevivência das organizações.

O presente estudo pretende servir de apoio na implantação da responsabilidade social e ambiental em empresas, promovendo e construindo relações cooperativas e benéficas para a sociedade e a empresa. A responsabilidade social e ambiental nas organizações insere um conjunto de atitudes capaz de encontrar novas formas de administrar seus negócios, sendo assim um diferencial nas entidades que as praticam. Portanto, é a vez da responsabilidade social e ambiental ser fator chave para o desenvolvimento e crescimento de valores na sociedade.

\section{FUNDAMENTAÇÃO TEÓRICA}

No decorrer do presente estudo apresenta-se a fundamentação teórica do tema, mostrando a construção histórica do conceito, as principais formas de atuação social das empresas e as principais ações de responsabilidade social empresarial.

\section{Responsabilidade social}

A abordagem do desempenho social empresarial teve seu surgimento nos primórdios do século $\mathrm{XX}$, com a filantropia. Logo após terminar o modelo industrial e o desenvolvimento da sociedade pós-industrial, o conceito prosperou, passando a integrar as expectativas dos agentes sociais no plano de negócios das organizações. Além da filantropia, passou-se a compreender voluntariado empresarial, cidadania corporati-

ReMAS • Revista Metodista de Administração do Sul, v. 2, N. 1, 2017 
va, responsabilidade social corporativa e, o desenvolvimento sustentável (TENÓRIO, 2006).

Segundo Borger (2001), a ideia de responsabilidade social originou-se na década de 1950, quando a literatura sobre responsabilidade social corporativa aparece nos Estados Unidos e Europa, a preocupação dos pesquisadores era com as empresas que não tinham consciência e nem responsabilidade pelos efeitos negativos do uso abusivo de poder nos negócios, como a degradação ambiental, a exploração do trabalho, o abuso econômico e a concorrência desleal. Para compensar os impactos negativos da atuação das empresas, empresários se envolveram em atividades sociais para beneficiar a comunidade fora do âmbito dos negócios das empresas, como sendo uma obrigação moral. Todos os envolvidos devem ser vistos e devem ser tratados como iguais, já que estes aspectos estão inter-relacionados. Da mesma maneira que o crescimento econômico não se mantém sem uma igualdade social e ambiental, programas sociais ou ambientais corporativos não continuarão em equilíbrio se não tiver uma empresa devidamente regulamentada.

Na década de 60, as discussões em torno do conceito de responsabilidade social começam a estender-se. Nesta fase percebeu-se uma visão de que a responsabilidade das organizações vai além de potencializar seus ganhos e introduz-se a esta a obrigação de uma conduta pública diante dos recursos econômicos e humanos da comunidade e a vontade de observar os recursos adotados para fins sociais mais extensos e não somente para interesses pessoais dos indivíduos (BERTONCELLO; CHANG JUNIOR, 2007).

Segundo Tenório (2006) a transformação da maneira de produção, gerada pela evolução tecnológica e pela utilização do conhecimento na sistematização do trabalho, foi outro elemento que contribuiu para estender a discussão do conceito de responsabilidade social empresarial. As relações de trabalho 
O PAPEL do gestor em UMA AUTARQUia PÚblica EM RELAÇÃo ÀS PRÁTICAS DE RESPONSABILIDADE SOCIAL E AMBIENTAL

obtiveram consequências na época criando debates no que se refere a obrigações das empresas e empregados.

Na década de 1980, segundo Tenório (2006), com a globalização e resgate da ideologia liberal, o conceito de responsabilidade social empresarial, sofre modificações onde se envolve de argumentos a favor do mercado. Nesta compreensão do conceito, o negócio é o ponto central responsável pela regularização e pesquisar as atividades empresariais coibindo prevalecimento por parte das companhias.

Segundo Laville (2009, p. 142) a época que marca o aparecimento propriamente dito do conceito de responsabilidade social empresarial se expandiu em meados dos anos 1990 a meados dos anos 2000: “se qualificou pelo engrandecimento da abordagem predominante, com uma postura mais perspicaz de defesa da ecoeficiência e de prevenção de riscos." As organizações foram confrontadas com indagações internas e externas acerca do impacto causado pelos problemas de seus próprios desempenhos institucionais, que seriam: produção, RH e compras. Mostrando coerência entre atitudes de práticas e valores, as empresas começam a potencializar estratégias de responsabilidade socioambiental, que passa pela adesão a códigos de conduta voluntários direcionados para práticas corporativas.

Ao discutir a responsabilidade social, Tachizawa (2006) destaca que esta se trata de novo modelo de gestão de pessoas, demandando novas necessidades em termos de: higiene e segurança no trabalho, treinamento e desenvolvimento de pessoal, planejamento de carreira, estratégia de cargos e salários, clima organizacional e qualidade de vida.

Existem visões bastante diferentes sobre a responsabilidade social empresarial, para Ashley (2005), responsabilidade social corporativa é a característica que melhor define o modo como os negócios são feitos, valores éticos e morais sempre

ReMas - Revista Metodista de Administração do Sul, v. 2, N. 1, 2017 
influenciaram as atitudes das empresas, mas estão se tornando cada vez mais rigorosos.

Nas conceituações apresentadas nota-se que existem muitas definições para responsabilidade social, reafirmando a diversidade e dificuldade de compreensão sobre o que é e o que significa, pode assim também ser confundida com filantropia, onde tem se discutido muito a respeito.

Segundo Melo Neto e Froes (1999, p. 102) a responsabilidade social de uma empresa consiste na "decisão de participar mais diretamente das ações comunitárias na região em que está presente e minorar possíveis danos ambientais decorrentes do tipo de atividade que exerce." Além disso, a RSE tem a ver com a consciência social e o dever cívico onde as ações de responsabilidade social empresarial refletem a ação de uma empresa em benefício da cidadania. A empresa que a pratica solidifica uma atitude de respeito e impele a cidadania corporativa, associando assim o exercício da responsabilidade social e o exercício da cidadania empresarial (MELO NETO; FROES, 2004).

Para Machado Filho (2006, p. 16), “a responsabilidade social confunde-se muitas vezes com ações sociais, esse apontamento é inadequado alterando a essência do que se espera de uma conduta socialmente responsável das empresas." A expressão responsabilidade social corporativa se atribui de forma mais ampla, as decisões de negócios com base em valores éticos que integram as dimensões legais, o respeito pelas pessoas, comunidades e meio ambiente.

O Instituto Ethos de Empresas (ETHOS) que é uma organização não governamental, criada com o intuito de sensibilizar as empresas a conduzir seus negócios de forma socialmente responsável, distingue a responsabilidade social empresarial como forma de seguir os negócios que torna a empresa parceira e responsável pelo desenvolvimento social. A empresa 
O PAPEL do gestor em UMA AUTARQUia PÚblica EM RELAÇÃo ÀS PRÁTICAS DE RESPONSABILIDADE SOCIAL E AMBIENTAL

socialmente responsável é aquela que dispõe da capacidade de ouvir os interesses das diferentes partes, e conseguir associá-los ao planejamento e estratégia de suas operações, empenhando-se em acolher as demandas de todos, não apenas acionistas e ou proprietários.

Define assim o Instituto Ethos (2012, paginação irregular) a responsabilidade social como:

A forma de gestão pela ética e transparente da empresa como todos os públicos com os quais se relaciona. Também se caracteriza por estabelecer metas empresariais compatíveis com o desenvolvimento sustentável da sociedade preservando recursos ambientais e culturais para as gerações futuras, respeitando a diversidade e promovendo a redução das desigualdades sociais.

Segundo Alessio (2008, p. 71), a expressão "responsabilidade social das empresas é um comportamento dos indivíduos que fazem parte das empresas, acionistas, dirigentes, funcionários e colaboradores" que tomam as decisões, orientadas ou não por uma conduta ética, mas as atitudes terão efeitos seja a um dos stakholders seja a sociedade em geral.

Vale ressaltar que o conceito de responsabilidade social empresarial vai muito além de ação social, pois se associa ao fato de a organização ser responsável pelos impactos que suas práticas e ações geram no universo situado além do mercado, onde não se refere somente ao contexto da empresa em si. Sendo assim, é preciso concordar que responsabilidade social empresarial é à maneira de gestão que se interpreta pela relação ética e transparente da empresa com todos os públicos com os quais ela se envolve, e pela determinação de metas empresariais adaptáveis para o desenvolvimento sustentável da sociedade, protegendo recursos ambientais e culturais para gerações futuras, respeitando a diversidade e favorecendo a redução de desigualdades sociais (GELMAN; PARENTE, 2008).

ReMAS • Revista Metodista de Administração do Sul, v. 2, N. 1, 2017 


\section{Ações de responsabilidade social empresarial}

Uma das questões que as empresas no Século XXI, enfrentam é: se deve ou não divulgar as ações de responsabilidade social praticadas pela mesma. Ás vezes a divulgação da mesma pode ter efeito contrário. Questiona-se muito a exploração rentável da pobreza, dos problemas alheios, o que vem passando por discussões éticas (BERTONCELLO; CHANG JUNIOR, 2007).

O exercício da responsabilidade social tem dois pontos centrais diferentes: os projetos sociais e as ações comunitárias. Segundo Melo Neto e Froes (2004, p. 29) "projetos sociais são empreendimentos voltados para a busca de soluções de problemas sociais que afligem populações e grupos sociais numerosos ou em situações de alto risco."

Ainda para Melo Neto e Froes (2004) as ações comunitárias equiparam-se a participação da empresa em programas e campanhas sociais geradas pelo governo, entidades filantrópicas e comunitárias. As atividades ocorrem por meio de doações, trabalhos voluntários de seus colaboradores e também por ações de apoio.

Explana-se que boas decisões empresariais podem resultar de decisões morais ou éticas. A ética é uma característica que toda a empresa cidadã deve ter, pois é um fator importante na realidade social. A organização deve agir de forma honesta com todos aqueles que têm algum relacionamento com ela, isso exige uma nova postura e, uma vez decidida à implantação de valores éticos, é preciso fazer ajustes internos, envolvendo mais diálogos e abertura para discutir possíveis divergências entre pontos de vista da direção e de seus empregados (TACHIZAWA, 2006).

Os projetos de responsabilidade social não são desenvolvidos apenas por empresas. Observam-se o exemplo da Associação Brasileira da Indústria Química (ABIQUIM) que lançaram o Projeto Plastivida que reúne 20 indústrias produto- 
O PAPEL do gestor em UMA AUTARQUia PÚblica EM RELAÇÃo ÀS PRÁTICAS DE RESPONSABILIDADE SOCIAL E AMBIENTAL

ras de resina termoplástica num grande trabalho de educação ambiental e de apoio as cooperativas catadoras de catadores de material plástico, favorecendo a reciclagem e colaborando para a criação de emprego e renda para a população carente (TACHIZAWA, 2006).

Segundo a ABIQUIM (2005), apenas 10\% do plástico colocado no mercado brasileiro é reciclado pós-consumo. Então se observa a importância desse projeto, no qual o setor investe milhões por ano, pois só com educação ambiental aumentará o índice de recuperação e reciclagem do material plástico consumido no país (TACHIZAWA, 2006).

A empresa Avon (higiene, limpeza e cosméticos) implantou o Fundo Avon e UNIFEM, com a formação do convênio com o Fundo das Nações Unidas para a Mulher (UNIFEM), a concretização de ações que promovam o fortalecimento da cidadania feminina. O objetivo é contribuir para o acesso das mulheres a informações básicas sobre trabalho, cultura, educação e saúde, melhorando sua condição de vida e autoestima (TACHIZAWA, 2006).

No Rio Grande do Sul, também se pode destacar várias iniciativas empresariais. De acordo com pesquisas realizadas pelo IPEA (Instituto de Pesquisa e Economia Aplicada), 19\% das empresas pesquisadas na região Sul do país utiliza uma entidade fundada pela empresa para efetuar ações sociais, representando assim o maior percentual entre as regiões. Dentre elas pode-se destacar:

A Fundação Projeto Pescar, fundada em 1995, é uma organização sem fins lucrativos, mantida e amparada por instituições privadas e públicas, nacionais e internacionais. Sua missão é criar escolas profissionalizantes em empresas, para que adolescentes em risco social possam aprender e ter oportunidade de ser preparados para exercer uma profissão, ocasionando sua inclusão social (ALESSIO, 2008).

ReMAS • Revista Metodista de Administração do Sul, v. 2, N. 1, 2017 
A Fundação Maurício Sirotsky Sobrinho (FMSS) uma entidade privada sem fins lucrativos, atua desde 1987, procurando soluções que possam conter as desigualdades sociais, principalmente para crianças e adolescentes que se sentem excluídos do meio social, inserindo assim na sociedade e apoiando com projetos a fim de reduzir as desigualdades sociais. A FMSS tem como meta principal impulsionar o trabalho de empresas que aplicam recursos privados para fins públicos, importando-se em mudar a realidade do país (ALESSIO, 2008).

A Fundação Semear, criada em 1996 foi desenvolvida com o intuito de estimular o desenvolvimento social da região no Vale dos Sinos, obteve a participação de 33 empresários que criaram o projeto, hoje em dia 100 empresas participam de projetos sociais através de três programas: Desenvolvimento de Organizações Sociais, Desenvolvimento da Responsabilidade Social e Produção de conhecimento, onde a incumbência seja que as empresas busquem alternativas e soluções para a realidade social, advindo de uma visão de investimento social privado (ALESSIO, 2008).

A Parceiros Voluntários é outra organização não governamental, sem fins lucrativos, fundada em 1997 por empresários gaúchos, onde sua missão é disseminar, aumentar e qualificar o atendimento de demandas sociais pelo trabalho voluntário e visando melhor qualidade de vida no RS. Possui hoje mais de 850 instituições conveniadas, e 22.368 voluntários, onde parceiro voluntário é aquele indivíduo que é motivado pela solidariedade, doando assim seu tempo, trabalho e talento em virtude de interesses sociais, de maneira não-remunerada (ALESSIO, 2008).

A Federação das Associações das Comerciais e de Serviços do Estado do Rio Grande do Sul (FEDERASUL) lançou o Programa Gaúcho de Responsabilidade Social (PGRS) onde o intuito é de realizar comitês para discutir as formas de as 
O PAPEL do gestor em UMA AUTARQUia PÚblica EM RELAÇÃo ÀS PRÁTICAS DE RESPONSABILIDADE SOCIAL E AMBIENTAL

empresas praticarem as ações sociais e orientação para a solução de problemas sociais do Estado. O programa contribui para a disseminação de práticas empresarias voltada a gestão da responsabilidade social nos negócios (FEDERASUL, 2015).

A responsabilidade social empresarial refere-se ao fato de como as organizações executam seus negócios. Para Oliveira (2008), a estrutura dos negócios lucrativos necessita estar integrada em um círculo vicioso que engloba a ética e a responsabilidade social. No entanto, a sociedade consumidora atesta seu papel, constata e valoriza ações que são adotadas pela empresa, apoiando assim consumindo os produtos feitos por quem atua de forma responsável.

\section{Gestão ambiental}

Existe uma vasta gama de autores e conceitos sobre a gestão ambiental (GA), entretanto, foram reunidos apenas alguns para discorrer sobre as considerações que seguem.

A gestão ambiental para Oliveira (2008) evoluiu a partir das necessidades relativas aos sistemas de saneamento básico em resultado do crescimento da população nas cidades para assim aprofundar estudos e conhecimentos de gestão pelas áreas de engenharia de produção e administração.

Na visão de Dias (2009) a gestão ambiental é um processo, onde é a expressão na qual se denomina a gestão empresarial e se evita, na medida do possível, problemas para o meio ambiente. Em outras palavras, é a forma na qual a gestão deve ser responsável, sem causar danos, e não ultrapassar a capacidade carga que é a capacidade de resiliência do meio ambiente na qual se encontra a organização. Neste mesmo contexto, Coimbra (2007), aponta que a gestão ambiental da mesma forma segue como sendo um processo, ou seja, procura combinar as atividades humanas juntamente com a qualidade e assim a preservação da riqueza ambiental, por intermédio das 
prioridades das necessidades sociais, destinando aos recursos práticas e mecanismos de avaliação e transparência.

Para Razzolini Filho e Zaperlon (2003) a ecogestão funciona como sendo um conjunto de elementos e ações pensadas com estratégias voltadas para a gestão do aspecto ambiental e ou sua preservação. Sendo assim, Coimbra (2007) afirma que compete ao poder público, á sociedade e as pessoas físicas a responsabilidade pelo intermédio do patrimônio ambiental fixado em um ponto territorial.

Desse modo, considerando o que foi referenciado, pode-se deduzir que para conduzir ambientalmente uma organização, é necessário compreender o compromisso de todos os envolvidos, ou seja, os stakholders onde existe a influência pelos resultados estratégicos e demandas ambientais da organização.

\section{Cultura e responsabilidade social empresarial}

Outro componente importante para o entendimento da responsabilidade social empresarial é a cultura, pois a partir dela é possível entender como as organizações vêm colocando em prática suas responsabilidades perante acionistas, funcionários, e sociedade em geral, levando em conta que toda a empresa faz parte de um contexto sociocultural mais amplo pelo qual ela se relacionará como esse ambiente no decorrer na sua existência (ASHLEY, 2005).

Para Orchis, Yung e Morales (2002), os impactos da cultura no comportamento organizacional da empresa estão ligados intrinsecamente a formação de sua estratégia. Com a análise de sua cultura é possível ver se existe o fator comprometimento da empresa, quanto à adoção de práticas socialmente responsáveis. 
O PAPEL do gestor em UMA AUTARQUia PÚblica EM RELAÇÃo ÀS PRÁTICAS DE RESPONSABILIDADE SOCIAL E AMBIENTAL

Ética empresarial em relação á responsabilidade social e ambiental

O termo ética significa costume, índole, maneira habitual de agir. A ética é parte da filosofia que estuda a moralidade dos atos humanos, foi fixado como indagação sobre natureza, fundamentada na moralidade. Existe também o entendimento sobre ética, como juízos morais, modelos e regras de conduta humana, com destaque na definição do que é certo e do que é errado (KARKOTLI; ARAGÃO, 2010).

Para Machado Filho (2006, p. 33) a ética é um padrão moral que salienta as consequências humanas das ações, "normalmente necessita de um comportamento que atinja padrões mais altos que os estabelecidos por lei, acima de ações calculadas para produzir um beneficio tangível." A ética trata de conceitos de valor, caracterizando a conduta humana do ponto de vista do bem ou do mal, seja em determinada sociedade, seja no modo absoluto.

Cabe ressaltar que a adoção da responsabilidade social e ambiental nas estratégias empresariais passa por um raciocínio sobre ética empresarial, visto que tal prática é um apontador de gestão empresarial que compreende a ética em suas atividades. Ashley (2005, p. 19) cita que a "ética é a parte que estuda a moralidade do agir humano livre, na forma de atos maus ou bons." Neste contexto a ética empresarial é a pesquisa da ética desenvolvida a atividade empresarial. Sendo assim passa pela inserção de valores morais a pessoa saber tomar decisões que irão agregar valores a sua empresa, a sua comunidade e a ela mesma.

Responsabilidade social e desenvolvimento sustentável

Estudos envolvendo a sustentabilidade estão cada vez mais ganhando espaços nas organizações, uma vez que geram 
preocupação sobre os impactos da atividade humana sobre a capacidade de carga do Planeta.

O conceito de sustentabilidade empresarial, objetiva aproximar os negócios, a sociedade e os ecossistemas na busca pelo desenvolvimento sustentável. No que se refere as perspectivas da sustentabilidade empresarial, Almeida (2002) explana que a dimensão econômica se relaciona com a saúde financeira da organização no curto e no longo prazo e também com seus acionistas e investidores. Na dimensão ambiental as organizações se estimulam a avaliar seus impactos ambientais ocasionados pelas atividades realizadas sobre o meio ambiente colaborando assim para a integração da administração ambiental no dia-dia do trabalho. Quanto à dimensão social, destaca ainda Almeida (2002) que se relaciona com as qualidades dos seres humanos, envolvendo tanto o ambiente interno da empresa quanto o externo, ou seja, leva em conta o relacionamento da empresa com todas as suas partes interessadas.

O princípio da sustentabilidade apela para um forte interesse próprio. De forma geral, está inserida na base tríplice do desempenho econômico, social e ambiental, ou seja, toda a organização deveria atuar com vistas a assegurar o desempenho econômico no longo prazo, impedindo um comportamento no curto prazo socialmente prejudicial ou ambientalmente irresponsável (GELMAN; PARENTE, 2008).

Num primeiro momento, o conceito de responsabilidade social empresarial estava ligado à ideia de que somente as grandes empresas são aptas de atender as questões sociais. Percebe-se que existe uma disposição para ter um comportamento socialmente responsável nas autarquias públicas bem como entender como funcionam tais entidades, que foram abordadas no item a seguir. 
Autarquia pública

A origem do termo autarquia se deu através do Decreto Lei № 6016/43, que elucidava como serviço estatal descentralizado, possuindo explícita ou implicitamente personalidade de direito público. O Decreto Lei 200 (BRASIL, 1967 apud COSTA, 2012, paginação irregular), define a autarquia:

Autarquia - o serviço autônomo, criado por lei, com personalidade jurídica, patrimônio e receita própria para executar atividades típicas da Administração Pública, que requeiram, para seu melhor funcionamento, gestão administrativa e financeira descentralizada.

Por fazer parte da Administração Pública Indireta, a autarquia é uma forma de descentralizar o serviço que foi subtraído da administração centralizada. As autarquias possuem imunidade tributária no que diz respeito aos impostos sobre patrimônio, renda e serviços ligados a suas atividades vitais (COSTA, 2012).

O surgimento de uma autarquia se efetiva unicamente por meio de uma lei específica conforme descrito na emenda constitucional 19/98. A criação de autarquia consolida diferentes regimes, seja em área jurídica ou administrativa, com o intuito de executar suas obrigações distinguindo-se das funções comuns da administração pública. Vale destacar que a autarquia ao surgir, auxilia na tarefa administrativa praticada pelo Estado (COSTA, 2012).

As atividades praticadas pelas autarquias estão dispostas no Decreto Lei 2000/67, que visa executar as atividades tipicamente administrativas, sob o regime do direito público, desconsiderando os de natureza econômica. Sendo assim, pode-se concluir que autarquia é uma forma de administração indireta, pois está ligada a administração central, não podendo legislar em relação a si. 


\section{METODOLOGIA}

A estratégia de pesquisa utilizada foi à pesquisa qualitativa, descritiva e do tipo estudo de caso, onde se buscou descrever as práticas de responsabilidade social e relacioná-las com o papel dos gestores do Conselho Regional de Administração (CRA/RS) na cidade de Porto Alegre. No processo investigatório, ocorreu o estudo de caso, que se caracterizou pelo delineamento do local onde foi realizado o estudo. Yin (2010) descreve que o estudo de caso é usado em muitas situações, além de contribuir para o conhecimento de fenômenos individuais, grupais, organizacionais, sociais e políticos, esse método de estudo permite que os pesquisadores mantenham as características globais e significativas dos eventos da vida real.

Sendo assim, quanto ao objetivo realizou-se uma pesquisa descritiva, que conforme Vergara (2000) é aquela em que o pesquisador expõe características de determinada população, ou de determinado fenômeno, podendo estabelecer relações entre fatos e definir sua natureza. Explana-se que a pesquisa descritiva busca a coleta de informações, analisa-a e apresenta num texto de acordo com o que procura atender aos objetivos do estudo. Portanto os métodos de pesquisa qualitativa, descritiva e estudo de caso apresentados tornaram-se relevantes para o estudo, por facilitar o entendimento do papel do gestor em relação as práticas de responsabilidades social e ambiental adotadas pelo Conselho Regional de Administração (CRA/RS).

A técnica de coleta de dados deste estudo efetuou-se pela entrevista, documentação e a observação direta. As entrevistas foram realizadas com a presidente da CRSS/CRA-RS, com o vice-presidente da CRSS/CRA-RS, com a gerente executiva do CRA/RS e com uma funcionária coordenadora da área administrativa. Após a utilização das técnicas para a coleta, e de posse das informações, os dados foram submetidos à análise e interpretação. 


\section{RESULTADOS}

Tendo em vista os objetivos desta pesquisa, os dados obtidos foram apurados e divididos nas seguintes subseções: caracterização da entidade estudada, perfil dos gestores relacionando-os com suas motivações para as ações de responsabilidade social desenvolvidas, ações de responsabilidade social que o Conselho Regional de Administração (CRA/RS) realiza e por fim a descrição do plano de ação do CRA/RS e sua inserção no seu planejamento estratégico.

\section{Perfil dos gestores relacionando suas motivações para} as práticas de responsabilidade social no CRA/RS

A gestão totalmente responsável é aquela que passa a mediar todo o âmbito organizacional, cada integrante que faz parte da entidade passa a aderir e se habituar de forma consciente a filosofia de responsabilidade social no seu dia-dia, como sendo um compromisso da organização que expressa a decisão de contribuir voluntariamente para uma sociedade melhor e um meio ambiente mais equilibrado e sadio.

De forma geral todos os gestores possuem graduação em administração de empresas, sendo que dois gestores participam da Câmara de Responsabilidade Social e Sustentabilidade, ambos possuem atividades em seu currículo voltadas para a excelência em ações sociais. No que diz respeito ao tempo médio dos gestores do CRA/RS constatou-se a média entorno de cinco anos de empresa, demonstrando desta forma a seriedade e o comprometimento dos gestores com no trabalho com a entidade. Dos quatro gestores entrevistados constatou-se que três são gestoras do sexo feminino e um gestor do sexo masculino.

Em entrevista realizada com um dos gestores da CRSS/ CRA-RS a motivação para atuar na área da responsabilidade social deu-se pela necessidade de contribuir para uma melhor gestão das organizações e seus recursos, ampliando assim a 
qualidade de vida e o bem-estar das gerações atuais e futuras (ENTREVISTADO A, 2015).

Outro gestor em entrevista mencionou que sua motivação para atuar na área de responsabilidade social é de que os gestores precisam criar condições de trabalho decente, onde por sua vez, as consequências serão melhores resultados para um todo. Mencionou de forma clara que as pessoas podem fazer algo para viver em um mundo melhor, mais justo, solidário e sustentável, pois as organizações dependem das pessoas e caminham lado a lado dos pilares da sustentabilidade. Ressaltou ainda que a motivação e o orgulho seja algo que deve vir de dentro de cada um dos colaboradores. Sendo assim falando de uma forma geral na visão do gestor entrevistado, quando o impacto social e ambiental da organização soar negativo os colaboradores buscam se afastar da organização ou até mesmo de sua profissão. Desta forma, o CRA/RS, preza por identificar as atitudes e o resultado de suas atividades na sociedade e na vida dos seus colaboradores, para que desta maneira ampliem a motivação do seu trabalho e junto com ele o sentimento de atuar com referência no ramo em que atua (ENTREVISTADO B, 2015).

Em outra entrevista realizada com gestora, as motivações para a implantação de ações de responsabilidade social no CRA/RS deu-se por estudar políticas, ações e estratégias envolvendo a responsabilidade social e a sustentabilidade (ENTREVISTADO C, 2015).

Já para outra gestora do CRA/RS as motivações para as práticas sociais são fortalecer laços entre comunidade e empresa por meio de confiabilidade, redução de problemas sociais, benefícios futuros para meio ambiente e mudança de cultura organizacional (ENTREVISTADO D, 2015).

De acordo com Melo Neto e Froes (2004) no comportamento ético social destacam-se três funções fundamentais da 
O PAPEL do gestor em UMA AUTARQUia PÚblica EM RELAÇÃo ÀS PRÁTICAS DE RESPONSABILIDADE SOCIAL E AMBIENTAL

organização a se cumprir, entre eles está formar os empregados com a consciência social, disseminar esses valores e estabelecer práticas e atitudes na empresa juntamente com fornecedores e parceiros.

Neste mesmo contexto Oliveira (2002) explanou que os profissionais mais qualificados e capacitados optariam por trabalhar em empresas que respeitem os direitos, segurança e qualidade de vida dos funcionários, demonstrando dessa maneira a importância da organização praticar e ser socialmente responsável.

Desta forma, percebeu-se nas entrevistas que de uma forma geral a principal motivação dos gestores para a incorporação e execução de práticas de responsabilidade social é a satisfação em fazer algo pelo meio ambiente e pela sociedade agindo para o bem-estar das gerações futuras e disseminando aos colaboradores e sociedade valores éticos e morais para um mundo mais solidário e sustentável. Portanto, a seguir foram descritas as ações de responsabilidade social no CRA/RS.

\section{Ações de responsabilidade social e ambiental do CRA/RS}

Com a coleta dos dados primários, ficaram comprovadas diversas práticas de responsabilidade social executadas pela autarquia, as quais foram descritas pelos gestores participantes da Câmara de Responsabilidade Social e Sustentabilidade do CRA/RS, salientando dessa forma a familiaridade com as ações desenvolvidas.

A seguir são descritos todos os programas realizados pelo CRA/RS.

A implantação do Sistema de Gestão Ambiental (SGA) teve início e criação no ano de 2011 apresentando como objetivo compartilhar ideias, atitudes e habilidades que incentivem práticas de RSE individuais e coletivas, engajando a entidade na opção pela responsabilidade social e sustentabilidade e

ReMAS • Revista Metodista de Administração do Sul, v. 2, N. 1, 2017 
subsidiando modelos de gestão de serviços. Para a obtenção do SGA no Conselho Regional de Administração, foram obedecidas algumas etapas e dentre elas foram destacadas a aplicação do questionário "Excelência ambiental", que teve o intuito de conhecer o grau de consciência ecológica dos gestores e colaboradores do CRA/RS e a utilização de ações e práticas de proteção ambiental (POLÍTICA DE RSE, 2015).

As iniciativas de novas adoções de práticas sociais e sustentáveis no CRA/RS tiveram início em 2011, no ano de 2012 o foco da atuação foi essencialmente ambiental já em 2013, o trabalho deu-se para os temas centrais de responsabilidade social e sustentabilidade.

Para a implantação do Sistema de Gestão Ambiental na autarquia, vários indicadores de responsabilidade foram de grande relevância, visto que deveria ser conhecido o grau de consciência ecológicas dos gestores e colaboradores do CRA/RS para isso foi aplicado o questionário ETHOS e de percepção ambiental. A estrutura do questionário ETHOS, oportuniza a empresa de planejar a forma de consolidar seu engajamento com a responsabilidade social. Com a aplicação deste questionário, foi percebido pelo Conselho de Regional de Administração que as ações de responsabilidade social podem se aperfeiçoar e no que diz respeito às questões ambientais a entidade pode incorporar ainda mais na sua gestão ações de sustentabilidade, se comprometendo a inserir a temática nas estratégias e na cultura organizacional da entidade (POLÍTICA de RSE, 2015).

Dentre as etapas do SGA, foi criado no CRA/RS adesivos para a conscientização sobre o meio ambiente, com o slogan "Preserve o meio-ambiente recicle sua mente" e "Ascenda essa ideia, ao sair da sala, desligue as luzes e os equipamentos". Foram confeccionados adesivos e fixados nos interruptores de luzes em todas as áreas do CRA/RS, com o intuito de 
O PAPEL do gestor em UMA AUTARQUia PÚblica EM RELAÇÃo ÀS PRÁTICAS DE RESPONSABILIDADE SOCIAL E AMBIENTAL

conscientizar todos na redução de energia e durabilidade dos equipamentos, conforme fotos disponibilizadas pelo CRA/RS abaixo (POLÍTICA DE RSE, 2015).

Dando sequência na apresentação de ações do sistema SGA de responsabilidade social foi adquirido pelo CRA/RS um recipiente adequado para coleta de pilhas e baterias que são descartadas na entidade, bem como organizado um espaço para armazenamento até o destino correto ao lixo contaminante (lâmpadas fluorescentes, pilhas, baterias etc.). Agindo de tal forma em se preocupar com a sociedade e o meio ambiente, a entidade comprova o conceito de que a ética da responsabilidade social é a capacidade de estimar as consequências para a sociedade conforme os autores Orchis, Young e Morales (2002).

Para reduzir o consumo de energia e ter melhor qualidade no ar, foi redimensionado o sistema de ar condicionado do CRA/RS adequando-os ao tamanho do ambiente ao número de pessoas e substituídos os que apresentavam maior ruído e consumo elevado de energia (POLÍTICA de RSE, 2015).

Observou-se no CRA/RS a reutilização do papel A4, onde foram criados blocos de rascunho, e os mesmos foram distribuídos para todos os setores, conscientizando assim os colaboradores sobre a importância de preservar o meio ambiente, percebeu-se que mensalmente se arrecada folhas usadas dos departamentos para a reutilização das mesmas (OBSERVAÇÃO, 2015).

A pesquisadora constatou em sua observação direta que o CRA/RS possui em sua entidade máquinas trituradoras para CIPs, CD's ou outros materiais sem reaproveitamento, onde são arrecadados esses materiais até o recolhimento do lixo seco, tal arrecadação ocorre semanalmente, visando assim o descarte correto do lixo e preservando o meio ambiente, nesta questão observou-se que a entidade faz sua parte no quesito ambiental (OBSERVAÇÃO, 2015). Conforme foto anexada abaixo.

REMAS • Revista Metodista de Administração do Sul, v. 2, N. 1, 2017 
Dentre as ações de responsabilidade social no CRA/RS foi criada uma cartilha explicativa para todos os colaboradores, a fim de conscientizar e disseminar a sustentabilidade com duas visões: a visão de uso de tais práticas para o lar e para o ambiente de trabalho, visando assim atitudes que gerem ações para dar continuidade nas práticas sustentáveis (DOCUMENTOS de RSE CRA/RS, 2015).

Afirmando este contexto os autores Orchis, Young e Morales (2001) explanam que os impactos da cultura no comportamento organizacional da empresa, estão ligados à definição de sua estratégia, e com a verificação da cultura é possível ver se existe o comprometimento para adotar tais práticas socialmente responsáveis.

A CRSS/CRA-RS realiza a formação de grupos de trabalho- GTs, onde objetiva a construção, inserção e acompanhamento das ações de gestão social e ambiental da entidade. Foram criados grupos compostos por colaboradores de diversas áreas de atuação, sendo assim estruturado por 2 grupos, o grupo 1 composto por 6 funcionários e 3 estagiários, que se responsabilizam pelos temas responsabilidade social, e grupo 2 composto por 3 funcionários, que atuam no tema sustentabilidade, os encontros são programados em um cronograma de atividades composta pelos próximos seis meses para cada grupo (POLÍTICA de RSE, 2015).

Neste mesmo contexto, foi constatado que a CRSS-RS organiza alguns encontros para ações de RSE no CRA/RS, onde são apresentados os resultados das ações realizadas e alguns ajustes que necessitam ser realizados são feitos com o intuito de melhorar as atividades, essa etapa é chamada de follow-up, ou seja, dar seguimento aos processos, visando à melhoria contínua das atividades praticadas (POLÍTICA DE RSE, 2015).

Tenório (2006) destacou que as empresas deveriam atuar de modo coletivo e profissional, explanou ainda que as organiza- 
O PAPEL do gestor em UMA AUTARQUia PÚblica EM RELAÇÃo ÀS PRÁTICAS DE RESPONSABILIDADE SOCIAL E AMBIENTAL

ções passam por transformações no que diz respeito a desempenho social. Já para o autor Tachizawa (2006) as organizações que aderem as práticas de responsabilidade social têm em seu perfil atitudes éticas, uma vez decididas à implantação de valores éticos a empresa cidadã tem como necessidade realizar ajustes internos, envolvendo diálogos e aberturas para discutir possíveis decisões entre o ponto de vista dos colaboradores e gestores, sendo assim percebeu-se que o conselho regional de administração apresentou essas tendências de práticas sociais realizando tais ações que foram apresentadas.

No ano de 2012 administradores e profissionais se reuniram para o Congresso Mundial de Administração, onde o assunto principal abordado foi o pacto global e sua contribuição da administração para uma sociedade mais justa e sustentável, esta iniciativa proposta pela Organização das Nações Unidas ONU teve o intuito de sensibilizaras organizações para a adoção de políticas de responsabilidade social e sustentabilidade. Para que o Pacto Global seja cumprido é necessária uma mobilização de dez princípios fundamentais, abordando temas como meio ambiente, direito humanos, direitos do trabalho e combate a corrupção. O sistema CFA/CRAs no ano de 2012 durante o congresso mundial de administração assinou uma carta assumindo seu compromisso com o programa: Pacto Global: a contribuição da administração para uma sociedade mais justa e sustentável, demonstrando assim a contínua preocupação na temática sustentabilidade (CRA/RS, 2012).

Ainda no ano de 2012 a assembleia legislativa do Estado do Rio Grande do Sul premiou a câmara de responsabilidade social e sustentabilidade concedendo o certificado de responsabilidade social pelo trabalho desenvolvido no âmbito social (CRA/RS, 2012).

Dentre as ações sociais desenvolvidas pelo CRA-RS foi verificado que desde 2010 o conselho realiza campanhas do

ReMAS • Revista Metodista de Administração do Sul, v. 2, N. 1, 2017 
agasalho, no ano de 2012 foram arrecadadas duas toneladas de roupas, já no ano de 2013 foram arrecadadas 2,5 toneladas de roupas na sede do CRA/RS para doações, essa parceria é desenvolvida juntamente com a defesa civil, que distribui as roupas para os necessitados. No ano de 2014 a campanha do agasalho intitulada "Esquenta Brasil" foi realizada no período da copa do mundo na sede do CRA/RS, onde mobilizaram administradores, colaboradores e voluntários em prol de quem necessita, nesta ocasião foram arrecadados duas toneladas de roupas. Todas as campanhas do agasalho são postadas no website do CRA/RS, redes sociais da entidade, bem como a distribuição de adesivos para a disseminação dessa ação na comunidade (CRA/RS, 2014).

Conforme Melo Neto e Froes (2004) o exercício de responsabilidade social visa também às práticas de ações sociais comunitárias, onde as organizações se engajam em participar de campanhas sociais promovendo o bem-estar da comunidade.

Destacou-se de forma notável que o CRA-RS/CRSS realiza ações para crianças carentes, a entidade anualmente arrecada brinquedos nos meses de outubro, ou seja, o mês da criança. O CRA/RS engaja seus colaboradores a arrecadar brinquedos para doações. No ano de 2013 a autarquia arrecadou em sua sede o total de 89 brinquedos. Quem organiza tais ações é o comitê do SGA sistema de gestão ambiental. Os brinquedos arrecadados são entregues na Pequena Casa da Criança localizada no bairro Partenon em Porto Alegre (CRA/RS, 2013).

No ano de 2014 foi realizado um curso nas Organizações das Nações Unidas (ONU) em Brasília em parceria com a Organização Internacional do Trabalho (OIT) a capacitação e formação de Multiplicadores para a promoção do Trabalho Decente e responsabilidade social onde o CRA/RS juntamente com a Câmara de Responsabilidade Social e Sustentabilidade estiveram presentes (CRA-RS, 2014). 
O PAPEL do gestor em UMA AUTARQUia PÚblica EM RELAÇÃo ÀS PRÁTICAS DE RESPONSABILIDADE SOCIAL E AMBIENTAL

Neste contexto para a autora Laville (2009) a responsabilidade social e ambiental reafirma a ideia de comprometimento da organização no dia-dia de suas atividades, para Karkotli e Aragão (2010) tais práticas de responsabilidade social como vistas no CRA/RS explanam a certeza de que a organização deve exercitar seu papel em se relacionar com a sociedade, conduzindo de maneira pró ativa a comunidade que está em sua volta.

O CRA/RS pratica ações sociais que vão além da filantropia, Mello Neto e Froes (2004) ressaltam que a filantropia vem de ações individuais e voluntárias, mas a responsabilidade social abrange o coletivo, envolve ações de funcionários, clientes, diretores e parceiros de uma organização. Neste mesmo sentido para Borger (2001) é preciso deixar claro que a responsabilidade social empresarial vai além da filantropia, pois não basta a empresa realizar ações sociais externas, ela deve estar engajada primeiramente em preocupar-se com questões internas da organização.

Plano de ação para a inserção da responsabilidade social $e$ ambiental no CRA/RS

Dando sequência na apresentação de resultados se obteve dados do mapa estratégico do CRA/RS que dá luz a informações atuais e futuras, sendo descritas a seguir.

O CRA/RS definiu seu mapa estratégico até ano de 2020. A missão do CRA/RS conforme dados obtidos no website é “promover a profissão da administração, registrar e fiscalizar o exercício das atividades do profissional para a defesa da sociedade". Se tratando da visão, o objetivo do CRA/RS é ser reconhecido como organização politicamente estruturada e garantidora da área de trabalho dos profissionais de administração para a defesa da excelência na gestão das organizações, e por fim tratando de valores a entidade preza por ética, com-

ReMAS - Revista Metodista de Administração do Sul, v. 2, N. 1, 2017 
petência, inovação, valorização da profissão administrador e participação (CRA/RS, 2015).

Dentro deste contexto, Tenório (2006) explana que a responsabilidade social quando inserida na cultura organizacional da empresa, influencia na maneira de planejar suas ações, projetos e valores, ressalta ainda que as melhores estratégias das empresas surgem diante de crises e incertezas, mostrando assim que a responsabilidade de ter princípios éticos e culturais influencia a forma de como a organização está preocupada em possuir um planejamento de ações. Desta maneira o CRA/RS mostrou comprometimento em definir suas estratégias inserindo nos componentes estratégicos valores éticos em sua gestão.

Conforme dados coletados em documentos e em seu website o CRA/RS insere a sustentabilidade em seu mapa estratégico, conforme anexo E onde seus processos internos mensuram atuar de forma sustentável na cadeia de valor. Para Laville (2009) a responsabilidade ambiental e ou social da organização ativa a ideia de comprometimento das atividades praticadas no seu dia-dia, além do mais esse movimento de senso de responsabilidade social se une das declarações da missão e políticas de comprometimento que justificam a razão de ser da organização além de conseguir lucros.

Dentro do planejamento estratégico do sistema CFA/CRA-RS foi definido que um plano de ação necessita possuir uma visão da qual a instituição está inserida. Para isso foi realizado uma análise do ambiente interno e externo da qual chamamos de análise SWOT (forças, ameaças, oportunidades e fraquezas) verificando assim quais aspectos internos e externos afetam a organização no seu desempenho estratégico. Tal análise SWOT possibilita a organização de adequar seus recursos e ter capacidade com o ambiente, oportunizando enfocar suas ações em áreas onde existam ameaças e ou oportunidades. A inserção de responsabilidade social na análise SWOT deu-se 
O PAPEL do Gestor em UMA AUTARQuia PÚblica EM RELAÇÃo

Às PRÁTICAS DE RESPONSABILIDADE SOCIAL E AMBIENTAL

nas oportunidades existentes, onde foi constatado a participação e o desenvolvimento de ações aplicadas ao pacto global (DOCUMENTOS, 2015).

Desta forma Tachizawa (2006) ressalta que o ambiente empresarial exige de seus gestores um senso de responsabilidade social e ambiental e deve envolver todos os colaboradores em prol dos objetivos efetivos. Sendo assim, as organizações que implantam em suas estratégias questões ligadas a responsabilidade social e ambiental terão vantagens significativas reduzindo seus custos e conservando uma postura socialmente responsável.

Em entrevista com a presidente da CRSS/CRA-RS a atuação na área da responsabilidade social se dá pela necessidade de contribuir para uma melhor gestão das organizações e seus recursos, ampliando assim a qualidade de vida e o bem-estar das gerações atuais e futuras. Percebe-se neste contexto que tais motivações estão intrínsecas e que tais ações serão benéficas se as organizações possuírem pessoas capacitadas para dar continuidade e engajar colaboradores em prol de tais ações (ENTREVISTADA A, 2015).

É nítido que fazer algo pela sociedade e pelo ambiente depende de estar associado aos valores e princípios gerados dentro de cada um. Tais valores motivam a realizar ações em prol da sociedade e inserir ela dentro do plano de ação das organizações (ENTREVISTADO B, 2015).

De acordo com verificação dos documentos do CRA/RS, constatou-se que a entidade considera de grande importância dar continuidade nas práticas ambientais e sociais da autarquia. Desta forma, a seguir foram descritas as ações futuras da entidade para a responsabilidade social.

\section{Ações futuras $x$ planejamento estratégico}

A seguir foram descritas as ações futuras relacionadas as práticas de responsabilidades sociais e ambientais da entidade.

ReMAS • Revista Metodista de Administração do Sul, v. 2, N. 1, 2017 
Dar continuidade no levantamento de custos dos itens consumíveis e materiais de expediente e elaboração de gráfico a ser apresentado para o comitê da CRSS e os funcionários em cada trimestre para constatação dos resultados obtidos (DOCUMENTOS, 2015).

Monitorar por meio de quadro de indicadores o consumo de materiais de copos plásticos, guardanapos, papel toalha e sacos de lixo, materiais de expediente como: folhas, tonners, lâmpadas e pilhas e consumo de energia elétrica, a ser disponibilizada no mural que se encontra na recepção para conhecimento de todos os colaboradores, demonstrando desta forma a importância que o CRA/RS envolve seus funcionários com a percepção dessas ações (DOCUMENTOS, 2015).

Nesta concepção Ashley (2005) ressalta que as organizações constroem relações de confiança regendo suas atitudes por normas de conduta, incentivando e adotando parcerias que agreguem valor considerando aspectos econômicos, ambientais e sociais.

Dentro deste contexto de ações futuras foi constatada em documentos a importância da conscientização através de reposição dos adesivos quando necessário, bem como adotar política de desligar computadores, monitores, estabilizadores, lâmpadas e/ou otimizar o uso das mesmas, e de aparelhos de ar condicionado a fim de redução do consumo de energia (DOCUMENTOS, 2015).

Dentre as ações futuras, insere-se a elaboração de novos programas como os cursos realizados pelo CRA/RS bem como a disseminação do curso multiplicadores do trabalho decente, visando assim o compromisso do CRA/RS para a multiplicação do conhecimento adquirido. Em entrevista com o vice- presidente da câmara de responsabilidade e sustentabilidade do CRA/RS em breve serão lançados pelo CFA/CRAs documentos e cadernos com todo esse conhecimento a fim de multiplicar 
O PAPEL do Gestor em UMA AUTARQuia PÚblica EM RELAÇÃo Às PRÁTICAS DE RESPONSABILIDADE SOCIAL E AMBIENTAL

e disseminar o que foi adquirido no curso de capacitação na ONU e assim os participantes do curso, passarem a ser multiplicadores em defesa do trabalho decente (ENTREVISTADO B, 2015).

Constatou-se em observação na entidade que foi disseminado a todos os colaboradores a dar continuidade na separação semanal do lixo reciclável e descarte aos arrecadadores de lixo seco, conforme previsto nas coletas que são realizadas nas quartas e sextas-feiras, também verificar empresas que busquem material contaminante como lâmpadas fluorescentes, pilhas, baterias e etc. (OBSERVAÇÃO, 2015).

Com o intuito de preservação do meio ambiente, o CRA/ RS dentre as ações a serem implantadas vê a necessidade do plantio de mudas de árvores no CRA/RS, com o intuito da neutralização de carbono o CO2 (DOCUMENTOS, 2015).

Os resultados das ações implantadas pelo sistema SGA que ainda estão em andamento demonstram que foi possível engajar os colaboradores para realizar tais ações de práticas sustentáveis.

Portanto, o planejamento das ações e a verificação da sua execução, bem como a continuidade dos projetos puderam ser observados nas respostas das entrevistas com os gestores, análise dos documentos coletados e também na observação direta não participante no $\mathrm{CRA} / \mathrm{RS}$, mostrando assim a preocupação da entidade em manter as práticas de responsabilidade social e ambiental.

Robbins (2005) ressalta que a cultura organizacional da empresa se refere na forma de como os funcionários compreendem a implantação das questões para as ações sociais, pois elas dependem de atitudes e comportamentos dos funcionários.

Conforme explanado no capítulo 4, foram obtidos neste estudoa caracterização da autarquia pesquisada, o perfil dos gestores e suas motivações para as práticas de RSE, as ações

ReMAS • Revista Metodista de Administração do Sul, v. 2, N. 1, 2017 
de responsabilidade social do CRA/RS, e a descrição do plano de ação da autarquia bem como sua inserção de RSE no planejamento estratégico do CRA/RS.

Desta forma, no próximo capítulo foram abordadas as considerações finais e sugestões desta pesquisa.

\section{CONSIDERAÇÕES FINAIS}

O pressuposto desta pesquisa foi a verificação do papel do gestor em relação aspráticas de responsabilidade social e ambiental no conselho regional de administração. Objetivou descrever as práticas e explanar as ações e motivações dos gestores da autarquia, ainda foram observadas ações no plano de ação com intuito de melhorias contínuas da organização. Dessa forma, a pesquisa contribuiu principalmente para que a empresa dê continuidade na realização das práticas de RSE. Além da contribuição do tema, este estudo, permitiu constatar e fortalecer as ações de responsabilidade social e ambiental na teoria e na prática.

Um dos processos mais importantes relacionado ao assunto discutido é o da conscientização dos colaboradores quanto à importância de se tomar decisões e implementar ações que promovam a sustentabilidade dentro da instituição.

$\mathrm{Na}$ autarquia pesquisada dentre os seus os programas realizados pela CRSS/CRA/RS, verificou-se que a entidade pratica e avalia as ações de responsabilidade social e estão engajados com o intuito de disseminar á seus colaboradores bem como a todos da comunidade e do sistema de CFA/CRAs existentes no Brasil, tornando-se assim referência nacional de responsabilidade social e sustentabilidade.

Dentre as motivações para as práticas de responsabilidade sociais e ambientais, os gestores mantêm intrínseca a ideia de fortalecer os laços entre a sociedade e empresa, considerando benefícios futuros para o meio ambiente, mudança de cultu- 
O PAPEL do gestor em UMA AUTARQUia PÚblica EM RELAÇÃo Às PRÁTICAS DE RESPONSABILIDADE SOCIAL E AMBIENTAL

ra organizacional e tornando assim um mundo mais justo e sustentável.

Referente às ações de responsabilidade sociais do CRA/ RS observou-se na entidade que o conselho se engaja em prol dessas atividades sociais e práticas de responsabilidade social. Academicamente, percebeu-se que o entendimento de uma organização que pratica a RSC não é aquela que faz ações para a sociedade, mas sim tem preocupações de que cumpre suas obrigações legais, sendo ética com os funcionários, com os clientes e com os fornecedores, e ainda aperfeiçoa e apoia ações sociais em sua comunidade, tendo consciência das questões sociais que entusiasmam a sua atuação e segue uma posição proativa perante suas responsabilidades.

Percebeu-se que a responsabilidade social quando inserida na cultura organizacional da empresa, influencia na maneira de planejar suas ações, projetos e valores, mostrando assim que a responsabilidade de ter princípios éticos e culturais influencia na forma de como a organização está preocupada em possuir um planejamento de ações. Desta maneira o CRA/ RS mostrou comprometimento em definir suas estratégias inserindo nos componentes estratégicos e valores éticos em seu plano de ação.

É importante destacar que esta pesquisa poderá servir como incentivo de engajamento de responsabilidade social e ambiental a outras entidades, e para que as organizações percebam que realizar tais ações é estar de acordo que não precisa que a empresa não tenha inúmeros projetos, mas sim que tenha desejo de querer fazer a diferença, partindo com pequenas ações, e que a partir dessas aumentem e sejam aos poucos sendo avaliadas pelo seu resultado, e que envolvam todos os colaboradores.

Entende-se que uma limitação do estudo foi que para a realização da coleta de dados a pesquisadora não dispôs de

ReMas - Revista Metodista de Administração do Sul, v. 2, N. 1, 2017 
muito tempo, visto que o fator tempo foi bastante relevante para as coleta de informações, embora não se tenha obtido o total êxito na coleta de informações todos os participantes deram atenção para a realização da pesquisa e verificação das práticas de responsabilidade sociais praticadas.

Embora o Conselho Regional de Administração do RS realize campanhas e ações sociais e ambientais, constatou-se que a entidade poderia futuramente inserir um projeto social conforme o levantamento de dados e de necessidades da comunidade a fim de alinhar suas estratégias de acordo com o seu plano de ação.

Como sugestão para implantação de um projeto no CRA/ RS, propõe-se que se insira na entidade o Projeto Pescar, no qual sua missão é criar escolas profissionalizantes em empresas, para que adolescentes em risco social possam aprender e ter oportunidades de serem preparados para exercer uma profissão, provocando sua inclusão social, contribuindo assim para o desenvolvimento social da comunidade. Desta maneira o CRA/RS agregaria e incluiria na vida dos jovens excelentes oportunidades para atividades futuras.

Como sequência a esta pesquisa sugere-se que sejam feito questionários com todos os colaboradores do CRA/RS com o intuito de ver o quão engajados estão para práticas sociais e inserção de projetos sociais e ambientais voltados para a comunidade.

Outra importante sugestão seria a implantação do programa A3P Agenda Ambiental na Administração Pública - A3P é um programa, coordenado pelo Ministério do Meio Ambiente, com a finalidade de promover a responsabilidade socioambiental e a adoção de procedimentos, referenciais de sustentabilidade e critérios socioambientais nas atividades do setor público, o intuito da A3P é incentivar os órgãos governamentais a se posicionarem e assumir um processo de gestão 
O PAPEL do Gestor em UMA AUTARQuia PÚblica EM RELAÇÃo

Às PRÁTICAS DE RESPONSABILIDADE SOCIAL E AMBIENTAL

exemplar para a sociedade, sendo os grandes multiplicadores da inclusão de processos administrativos resultando em melhoria do bem-estar das pessoas e igualdade social e reduzindo significativamente, riscos ambientais e escassez ecológica.

Cabe ressaltar que a entidade evidencia o que está alinhado com a autora Ashley (2005) de que a responsabilidade social incide em se ter compromisso para a sociedade e que tal compromisso reflete nas ações e atitudes que afetam de forma positiva a comunidade.

Este presente trabalho ligou a teoria e a prática afirmando, conforme dados obtidos no CRA/RS que a organização verificada está seguindo no caminho correto, onde os gestores se empenham em colocar a responsabilidade social e ambiental em seus projetos e ações, e os mesmos continuam sendo desenvolvidos e avaliados constantemente. Portanto o desafio da entidade está em manter, atualizar e ampliar suas práticas de ações sociais e ambientais já existentes.

A importância de existir uma gestão totalmente voltada para a responsabilidade social e ambiental no âmbito empresarial e com pessoas que estejam engajadas em prol de uma causa comum torna-se um fator decisivo para melhoras na sociedade em geral. Como foi percebida a responsabilidade social e ambiental, vai além de atividades e ações, ela envolve muito mais das organizações além de fazer a diferença na sociedade e no meio ambiente.

\section{REFERÊNCIAS}

ALESSIO, R. Responsabilidade Social das empresas no Brasil: Reprodução de postura ou novos rumos? Porto Alegre: EDIPUCRS, 2008.

ASHLEY, P. A. Ética e responsabilidade social nos negócios. 2. ed. São Paulo: Saraiva, 2005. 
BORGER, F. G. Responsabilidade social: efeitos da atuação social na dinâmica empresarial. 2001.Tese (Doutorado) - Universidade de São Paulo, São Paulo, 2001. Disponível em: <http://www.teses.usp. br/teses/disponiveis/12/12139/tde-04022002-105347/pt-br.php>. Acesso em: 25 abril 2015.

COIMBRA, J. Imagem e Percepção ambiental. Curso de gestão ambiental. $1^{\circ}$ ed. São Paulo: Manoli, 2007.

COSTA, D. J. da. A Autarquia na Administração Pública Indireta. Conteúdo Jurídico, Brasília-DF: 01 nov. 2012. Disponível em: <http:// www.conteudojuridico.com.br/?artigos\&ver=2.40255\&seo=1>. Acesso em: 03 out. 2015.

CFA. Valores do CFA.2015a. Disponível em: <http://www.cfa.org. br/institucional/conselho-federal/valores-do-cfa>. Acesso em: 28 de set. de 2015.

CFA. Finalidade. 2015b. Disponível em:<http://www.cfa.org.br/institucional/conselho-federal/finalidade>.Acesso em: 28 de set. 2015.

CRA/RS. Administradores se reúnem para discutir pacto global. 2015. Disponível em: <http://www.crars.org.br/noticias/administradores-se-reunem-para-discutir-pacto-global-1786>. Acesso em: 26 set. de 2015.

CRA/RS. Assembléia Legislativa do RS concede Certificado de Responsabilidade Social 2012 ao CRA/RS. Disponível em: <http://www. crars.org.br/crss/noticias_interna?id=191>. Acesso 26 de set. de 2015.

CRA/RS. CRSS é representada pelo seu vice-presidente no curso multiplicadores do trabalho decente em parceira do CFA/CRA's com a OIT e ONU. 2015. Disponível em: <http://www.crars.org.br/ crss/imprimir?id=249>. Acesso 26 out. 2015.

DIAS, R. Gestão ambiental social e sustentabilidade. São Paulo: Atlas, 2009.

ETHOS. Valores, Transparência e Governança. Disponível em: <http://www3.ethos.org.br/conteudo/gestao-socialmente-responsavel/ valores-transparencia-e-governanca/\#.VXNiH89Viko>. Acesso em: 28 abril 2015.

FEDERASUL. Federasul Institucional: Uma história ao lado do desenvolvimento econômico e social. Disponível em: <http://www. federasul.com.br/institucional/institucional.asp >. Acesso em: 16 abril 2015. 
O PAPEL do Gestor em UMA AUTARQuia PÚblica EM RELAÇÃo

ÀS PRÁTICAS DE RESPONSABILIDADE SOCIAL E AMBIENTAL

MACHADO FILHO, C. P. (2006). Responsabilidade Social e Governança Corporativa: o debate e as implicações: A responsabilidade social, instituições, governança e reputação. São Paulo: Pioneira, Thomson Learning, 2006.

KARKOTLI, G.; ARAGÃO, S. D. Responsabilidade Social: Uma contribuição à gestão transformadora das organizações. Petrópolis, RJ: Vozes, 2004.

LAVILLE, E. A empresa verde. São Paulo: 2009.

MELO NETO, F. P. de; FROES, C.. Gestão da responsabilidade social corporativa: o caso brasileiro. 2. ed. Rio de Janeiro: Qualitymark, 2004.

Responsabilidade social e cidadania empresarial: a administração do terceiro setor. Rio de Janeiro: Qualitymark, 1999.

OLIVEIRA, J. A. P. Empresas na Sociedade: Sustentabilidade Responsabilidade Social. Rio de Janeiro: Elsevier, 2008.

OLIVEIRA, M. A. L. SA 8000: o modelo ISO 9000 aplicado a responsabilidade social. Rio de Janeiro: Qualitymark, 2002.

RAZZOLINI FILHO, E.; ZAPERLON, M. I. Dicionário de administração de A á Z. São Paulo: Juruá, 2003.

ROBBINS, Stephen P. Comportamento Organizacional. 11. ed. São Paulo: Pearson Prentice Hall, 2005.

TACHIZAWA, T. Gestão ambiental e responsabilidade corporativa: Estratégias de negócios focadas na realidade brasileira. 4. ed. São Paulo, 2006.

TENÓRIO, F. G. Responsabilidade social empresarial: Teoria e prática. 2. ed. Rio de Janeiro: FGV, 2006.

YIN, R. K. Estudo de caso: Planejamento e métodos. 3. ed. Porto Alegre: Bookman, 2005. 